\title{
STUDI KOMPARATIF HASIL BELAJAR MATEMATIKA SISWA BERDASARKAN JURUSAN
}

\author{
${ }^{1}$ Nouri Alfin Nabilah, ${ }^{2}$ Yunita Nury Wulandari, ${ }^{3}$ Hilda Amalia Pangertika,,${ }^{4}$ Umi \\ Farihah \\ ${ }^{1,2,3,4}$ Program Studi Tadris Matematika Institut Agama Islam Negeri Jember \\ Jalan Mataram No.1, Karang Miuwo, Mangli, Kec. Kaliwates, Kab. Jember, Jawa Timur 68136 \\ Email : ${ }^{1}$ nourialfin@gmail.com
}

\begin{abstract}
Abstrak
Penelitian ini bertujuan untuk mengetahui perbandingan hasil belajar matematika siswa pada masing-masing jurusan. Tempat penelitian adalah di Madrasah Aliyah Negeri 1 Jember. Subjek pada penelitian ini adalah seluruh siswa kelas XI pada semua jurusan di MAN 1 Jember. Metode yang digunakan dalam penelitian ini adalah kuantitatif, dengan teknik pengumpulan data menggunakan dataset statistic yang didapat dari hasil ulangan harian matematika kelas XI KD 3.3 tentang menjelaskan matriks dan kesamaan matriks dengan menggunakan masalah kontekstual dan melakukan operasi pada matriks yang meliputi penjumlahan, pengurangan, perkalian skalar, dan perkalian, serta transpose. Teknik analisis data menggunakan analisis kuantitatif inferensial dengan uji One-Way Anova. Hasil dari penelitian ini adalah diketahui adanya perbedaan hasil belajar matematika siswa disetiap jurusan, yakni jurusan Matematika-Ilmu Pengetahuan Alam (MIPA), Ilmu Pengetahuan Sosial (IPS), Program Keagamaan (PK), Bahasa, dan Bina Insan Cendekia (BIC). Jurusan sangat berpengaruh pada hasil belajar matematika, jika dilihat dari segi kemampuan nalar matematika maka jurusan BIC dan MIPA yang paling besar nilai hasil belajar matematikanya.
\end{abstract}

Kata Kunci: Hasil Belajar Matematika, Jurusan, Perbandingan

\section{Abstract}

This study aims to determine the comparison of student mathematics learning outcomes in each department. The place of research is at MAN 1 Jember. The subject in this study was all students of class XI at all department in MAN 1 Jember. The method used in this study is quantitative, with data collection techniques using statistical datasets obtained from the results of the class XI with KD 3.3 about explaining the matrix and similarities of the matrix using contextual problems and operations on the matrix. Data analysis techniques use inferential quantitative analysis with the One-Way Anova test. The results of this study are known to be a difference in student mathematics learning outcomes in all department, namely the Department of MIPA, IPS, religious, language and BIC programs. Departments are very influential on mathematics learning outcomes, if viewed in terms of the ability of mathematical reason, the BIC and MIPA department are the greatest value of mathematical learning outcomes.

\section{PENDAHULUAN}

Pendidikan mempunyai peran yang sangat strategis dalam meningkatkan kualitas sumber daya manusia dan upaya mewujudkan cita-cita bangsa Indonesia dalam mewujudkan kesejahteraan umum dan mencerdaskan kehidupan bangsa. Usaha untuk meningkatkan pembangunan sumber daya manusia melalui pendidikan perlu mendapat perhatian khusus. Undang-undang Pendidikan No. 20 Tahun 2003 tentang Sistem Pendidikan Nasional yang berfungsi mengembangkan kemampuan, membentuk watak dan peradaban bangsa yang bermartabat dalam rangka mencerdaskan kehidupan bangsa. Hal ini bertujuan untuk 
mengembangkan potensi peserta didik agar menjadi manusia yang beriman dan bertaqwa kepada Tuhan yang Maha Esa berakal mulia, sehat, berilmu, cakap, kreatif, mandiri, menjadi warga negara yang demokratis dan peka terhadap tantangan zaman. Jadi jelaslah pendidikan merupakan kegiatan yang dilakukan dengan sengaja agar anak didik memiliki sikap dan kepribadian yang baik, sehingga penerapan pendidikan harus diselengggarakan sesuai dengan Sistem Pendidikan Nasional berdasarkan UU No. 20/ 2003.

Kegiatan belajar merupakan proses pendidikan di sekolah. Ini berarti bahwa berhasil tidaknya pencapaian tujuan pendidikan banyak bergantung kepada bagaimana pencapaian taksonomi pendidikan yang dialami siswa yang mencakup aspek kongnitif, afektif dan psikomotorik. Dalam suatu lembaga pendidikan keberhasilan proses belajar mengajar dapat dilihat juga dari prestasi belajar yang dicapai oleh peserta didik. Pendapat ini diungkapkan Fatimah (2011: 95) dalam majalah ilmiah mengatakan dalam konteks pembelajaran ada beberapa tolak ukur yang dapat digunakan untuk mengetahui prestasi belajar siswa. Salah satu tolak ukur yang digunakan adalah prestasi belajar yang mengacu pada pencapaian taksonomi pendidikan yang mencangkup aspek kognitif, afektif dan psikomotorik. Salah satu upaya yang menjadikan seseorang berprestasi adalah melakukan kegiatan yang berkelanjutan. Artinya, setelah seseorang menyadari potensi dirinya disuatu bidang maka ia akan terus menerus berusaha untuk mengembangkannya menjadi kemampuan utama. Prestasi adalah hasil dari usaha mengembangkan bakat secara terus menerus (Dahlan, 2008:59). Hasil belajar tersebut merupakan prestasi belajar peserta didik yang dapat diukur dari nilai siswa setelah mengerjakan soal yang diberikan oleh guru pada saat evaluasi dilaksanakan. Keberhasilan pembelajaran disekolah akan terwujud dari keberhasilan belajar siswa. Keberhasilan siswa dalam belajar dapat dipengaruhi oleh faktor dari dalam individu maupun dari luar individu. Menurut Ahmadi (2004: 138) prestasi belajar yang dicapai seseorang merupakan hasil interaksi berbagai faktor yang mempengaruhinya baik dari dalam diri (faktor internal) maupun dari luar diri (faktor eksternal) individu. Faktor dari dalam individu, meliputi faktor fisik dan psikis, diantaranya adalah minat siswa.

Menurut Hamalik (2009: 27) belajar adalah modifikasi atau memperteguh kelakuan melalui pengalaman (learning is defined as the modification or strengthening of behavior through experiencing). Menurut Santoso (2000: 39) belajar adalah proses interaksi dan bukan sekedar proses penyerapan yang berlangsung tanpa usaha yang aktif dari individu yang belajar. Menurut Shaleh (2009: 207) belajar adalah suatu bentuk pertumbuhan atau perubahan dalam diri seseorang yang dinyatakan dalam cara-cara bertingkah laku yang baru berkat pengalaman dan latihan. Menurut Hilgrad dan Brower yang dikutip oleh Shaleh (2009: 
207-208) bahwa belajar berhubungan dengan perubahan tingkah laku seseorang terhadap suatu situasi tertentu yang disebabkan oleh pengalamannya secara berulang-ulang dalam situasi itu, dimana perubahan tingkah laku itu tidak dapat dijelaskan atau dasar kecenderungan respon pembawaan, kematangan, atau keadaan-keadaan sesaat seseorang (misalnya : kelelahan, pengaruh obat, dan sebagainya). Menurut Gagne yang dikutip oleh Shaleh (2009: 208) bahwa belajar terjadi bila terdapat stimulasi yang bersamaan dengan ingatan mempengaruhi siswa sedemikian rupa hingga terjadi perubahan perbuatan dari sebelum ke sesudah ia mengalami suatu situasi. Dari berbagai pendapat para ahli tersebut, dapat diambil kesimpulan bahwa belajar merupakan proses perubahan tingkah laku dari sebelum ke sesudah mendapatkan stimulus pada rentang waktu tertentu.

Menurut Slameto (2003: 3) bahwa hasil belajar merupakan perubahan tingkah laku yang terjadi secara berkesinambungan dan tidak statis. Sedangkan menurut Dimyati dan Mudjiono (2002: 20) hasil belajar merupakan suatu puncak proses belajar. Hasil belajar merupakan suatu hal yang dapat dilihat dan diukur. Hal ini sesuai menurut Hamalik (2009: 28) yang menyatakan bahwa hasil belajar nampak sebagai terjadinya perubahan tingkah laku pada diri siswa yang dapat diamati dan terukur dalam bentuk perubahan pengetahuan, sikap dan keterampilan. Perubahan tersebut diartikan sebagai terjadinya peningkatan dan pengembangan yang lebih baik. Dengan demikian, hasil belajar merupakan perubahan tingkah laku setelah terjadi proses belajar dengan hasil yang dapat diamati dan diukur.

Menurut Suriasumantri (2009: 190) matematika adalah bahasa yang melambangkan serangkaian makna dari pernyataan yang ingin kita sampaikan. Lambang-lambang matematika bersifat artificial yang baru mempunyai arti setelah sebuah makan diberikan padanya. Menurut Wittgenstein yang dikutip oleh Suriasumantri (2009: 199) matematika adalah metode berpikir logis, artinya matematika merupakan suatu cara atau teknik yang digunakan dalam berpikir logis sehingga kebenaran dalam matematika merupakan kebenaran yang berdasarkan logika bukan empiris atau kenyataan. Hal ini karena objek yang dipelajari dalam matematika merupakan benda abstrak atau khayal seperti angka-angka dan simbolsimbol. Selain sebagai bahasa dan alat berpikir secara logika, matematika merupakan pengetahuan yang didasarkan pada pola deduktif, yakni pola berpikir dari hal umum menuju hal khusus, artinya ada sebuah teori kemudian dibuktikan secara spesifik dan terperinci dengan contoh-contoh. Demikian pula dalam pembelajaran matematika dimulai dari hal-hal yang konkrit kemudian hal-hal yang abstrak dan dari masalah-masalah mudah kemudian masalah-masalah sulit. Dapat ditarik garis besar bahwa matematika adalah ilmu tentang 
bilangan, bangun, hubungan-hubungan konsep, dan logika dengan menggunakan bahasa lambang atau simbol dalam menyelesaikan masalah dalam kehidupan sehari-hari.

Berdasarkan uraian tersebut di atas, maka disimpulkan bahwa hasil belajar matematika adalah puncak dari kegiatan belajar yang berupa perubahan dalam bentuk kognitif, afektif, dan psikomotor dalam hal kemampuan tentang bilangan, bangun, hubungan-hubungan konsep dan logika yang berkesinambungan serta dapat diukur atau diamati.

MAN 1 Jember merupakan Madrasah Aliyah Negeri di Kabupaten Jember yang terletak di J1. Imam Bonjol No.50, Kaliwates Kidul, Kaliwates, Kec. Kaliwates. Saat ini Madrasah tersebut telah memiliki lima jurusan yaitu jurusan Matematika-Ilmu Pengetahuan Alam (MIPA), Ilmu Pengetahuan Sosial (IPS), Program Keagamaan (PK), Bahasa, dan Bina Insan Cendekia (BIC). Penjurusan siswa ini bertujuan untuk mengarahkan peserta didik agar lebih fokus mengembangkan kemampuan diri dan minat yang dimiliki. Jurusan yang tidak tepat bisa sangat merugikan siswa dan karirnya di masa mendatang. Dengan penjurusan tersebut diharapkan dapat memaksimalkan potensi, bakat atau talenta individu, sehingga juga akan memaksimalkan nilai akademisnya. Penentuan jurusan ini akan berdampak terhadap kegiatan akademik selanjutnya dan mempengaruhi pemilihan bidang ilmu atau studi bagi siswa-siswi yang ingin melanjutkan ke perguruan tinggi nantinya. Penentuan jurusan yang dilakukan selama ini mempunyai banyak kelemahan, antara lain berdasarkan keinginan siswa tanpa melihat latar belakang nilai akademisnya. Sehingga jurusan yang dipilih terkadang menjadi masalah bagi siswa di kemudian hari, sebagai contoh nilai akademik yang tidak maksimal, pemilihan program studi saat melanjutkan ke jenjang perguruan tinggi yang terkendala akibat jurusan yang tidak sesuai, dan lain-lain.

Dari uraian latar belakang di atas, maka peneliti tertarik melakukan penelitian dengan judul "Studi Komparatif Hasil Belajar Matematika Siswa Berdasarkan Jurusan”.

\section{METODE PENELITIAN}

Metode yang digunakan dalam penelitian ini adalah kuantitatif, dengan teknik pengumpulan data menggunakan dataset statistic yang didapat dari hasil ulangan harian matematika kelas XI KD 3.3 tentang menjelaskan matriks dan kesamaan matriks dengan menggunakan masalah kontekstual dan melakukan operasi pada matriks yang meliputi penjumlahan, pengurangan, perkalian skalar, dan perkalian, serta transpose.

Penelitian ini merupakan penelitian komparatif, yang membandingkan antara dua variabel atau lebih. Variabel yang dianalisa atas dua hal yaitu variabel bebas dan variabel 
terikat. Variabel bebas dalam penelitian ini adalah lima jurusan yang ada di MAN 1 Jember, dan variabel terikatnya adalah hasil belajar matematika siswa.

Penelitian menggunakan data nilai yang populasinya adalah seluruh siswa kelas XI MAN 1 Jember di lima jurusan yang ada. Sampel yang diambil dalam penelitian ini dan disajikan dalam tabel 1.

\begin{tabular}{ccccccc}
\hline \multirow{2}{*}{ Angkatan } & \multicolumn{5}{c}{ Jurusan } & \multirow{2}{*}{ Jumlah } \\
\cline { 2 - 6 } & MIPA & IPS & PK & BHS & BIC & \\
\hline 2018 & 23 & 23 & 23 & 23 & 23 & 115 \\
\hline
\end{tabular}

Tabel 1. Jumlah sampel penelitian

Teknik analisis data menggunakan analisis kuantitatif inferensial dengan One-Way Anova. Uji Anova Satu Arah (One Way Anova) adalah jenis uji Statistika Parametrik yang bertujuan untuk mengetahui apakah terdapat perbedaan rata-rata antara lebih dari dua group sampel. Uji satu arah yang dimaksud dalam uji Anova ini adalah sumber keragaman yang dianalisis hanya berlangsung satu arah yaitu antar perlakuan (Between Group). Adapun faktor lain yang berpotensi mempengaruhi keragaman data dimasukkan kedalam Galat (within Group) dan sebisa mungkin dikontrol, sehingga jenis uji ini umumnya dilakukan pada rancangan perlakuan yang faktor-faktor lingkungannya dapat dikontrol. Untuk memudahkan dalam proses analisis data, peneliti menggunakan bantuan aplikasi IBM SPSS Statistics 22.

Dalam melakukan uji Anova harus dipenuhi beberapa asumsi, yaitu:

1. Sampel berasal dari kelompok yang independen.

2. Data masing-masing kelompok berdistribusi normal.

3. Varian antar kelompok harus homogen.

\section{HASIL DAN PEMBAHASAN}

\section{Pengujian Persyaratan Analisis}

Asumsi yang pertama harus dipenuhi pada saat pengambilan sampel yang dilakukan secara random terhadap beberapa kelompok yang independen, yang mana nilai pada satu kelompok tidak tergantung pada nilai di kelompok lain. Dalam hal ini, kelompok merupakan jurusan yang ada di MAN 1 Jember yakni jurusan MIPA, IPS, Program Keagamaan, Bahasa, dan BIC. Hasil belajar di setiap jurusan tidak tergantung pada jurusan yang lain, maka syarat bahwa sampel berasal dari kelompok yang independen sudah terpenuhi.

Uji Normalitas 
Tests of Normality

\begin{tabular}{|l|c|c|c|c|}
\hline \multirow{2}{*}{} & \multirow{2}{*}{ JURUSAN } & \multicolumn{3}{|c|}{ Shapiro-Wilk } \\
\cline { 3 - 5 } & & Statistic & df & Sig. \\
\hline $\begin{array}{l}\text { HASIL BELAJAR } \\
\text { MATEMATIKA SISWA }\end{array}$ & MIPA & .936 & 23 & .149 \\
& IPS & .929 & 23 & .106 \\
& PK & .933 & 23 & .126 \\
& BHS & .927 & 23 & .094 \\
& BIC & .947 & 23 & .257 \\
\hline
\end{tabular}

*. This is a lower bound of the true significance.

a. Lilliefors Significance Correction

Tabel 2. Hasil uji normalitas data menggunakan uji Shapiro-Wilk

Kriteria uji normalitas dengan SPSS :

Sig. $<0.05$ maka data berdistribusi tidak normal

Sig. > 0.05 maka data berdistribusi normal

Dari tabel diatas dapat dilihat pada kolom sig. bahwa kelima jurusan memiliki sig. lebih besar dari 0.05 yang berarti bahwa data masing-masing kelompok berdistribusi normal.

Uji Homogenitas

Test of Homogeneity of Variances

HASIL BELAJAR MATEMATIKA SISWA

\begin{tabular}{|c|c|c|c|}
\hline Levene Statistic & df1 & df2 & Sig. \\
\hline 1.195 & 4 & 110 & .317 \\
\hline
\end{tabular}

Tabel 3. Hasil uji homogenitas data 
Kriteria uji homogenitas dengan SPSS :

Sig. $<0.05$ maka varian antar kelompok tidak homogen

Sig. > 0.05 maka varian antar kelompok homogen

Dari tabel diatas dapat dilihat pada kolom sig. bahwa besar sig. lebih dari 0.05 yang berarti varian antar kelompok homogen.

\section{Pengujian Hipotesis}

Setelah tiga syarat uji analisis telah terpenuhi maka dapat dilanjutkan dengan uji hipotesis. Dalam hal ini menggunakan uji One-Way Anova karena data terdiri dari lima varian (MIPA, IPS, Program Keagamaan, Bahasa, dan BIC). Uji One-Way Anova ini dilakukan untuk mengetahui apakah terdapat perbedaan rata-rata hasil belajar matematika siswa antara kelima jurusan tersebut.

$\mathrm{H}_{0}=$ Tidak terdapat perbedaan hasil belajar matematika siswa yang signifikan akibat perbedaan jurusan

$\mathrm{H}_{1}=$ Terdapat perbedaan hasil belajar matematika siswa yang signifikan akibat perbedaan jurusan

ANOVA

HASIL BELAJAR MATEMATIKA SISWA

\begin{tabular}{|l|r|r|r|r|r|}
\hline & Sum of Squares & Df & \multicolumn{1}{c|}{$\begin{array}{c}\text { Mean } \\
\text { Square }\end{array}$} & F & Sig. \\
\hline Between Groups & 33044.522 & 4 & 8261.130 & 447.743 & .000 \\
Within Groups & 2029.565 & 110 & 18.451 & & \\
Total & 35074.087 & 114 & & & \\
\hline
\end{tabular}

Tabel 4. Hasil uji One-Way Anova

Kriteria uji homogenitas dengan SPSS:

Sig. $<0.05$ maka terdapat perbedaan rata-rata hasil belajar matematika siswa disetiap jurusan Sig. $>0.05$ maka tidak terdapat perbedaan rata-rata hasil belajar matematika siswa disetiap jurusan

Dari tabel diatas dapat dilihat pada kolom sig. bahwa besar sig. kurang dari 0.05 yang berarti $\mathrm{H}_{0}$ ditolak dan $\mathrm{H}_{1}$ diterima. Maka dapat dinyatakan bahwa terdapat perbedaan hasil belajar matematika siswa yang signifikan akibat perbedaan jurusan 
Pada uji One-Way Anova hanya menginformasikan bahwa secara keseluruhan terdapat perbedaan yang signifikan pada variabel respon (hasil belajar matematika siswa) akibat variabel peubah atau factor (jurusan), namun uji Anova tidak memberikan informasi yang spesifik tentang apakah taraf tertentu dari sebuah faktor berbeda dengan taraf lainnya, misalnya apakah taraf jurusan MIPA sama dengan taraf jurusan IPS. Untuk mengetahui perbedaan taraf yang signifikan pada setiap faktor dapat dilakukan uji lanjut atau Post Hoc.

Uji lanjut atau Post Hoc ini hanya dapat digunakan jika hasil uji Anova menyatakan $\mathrm{H}_{0}$ ditolak. Dalam hal ini, uji lanjut yang digunakan adalah uji LSD.

POST HOC TESTS

Multiple Comparisons

Dependent Variable: HASIL BELAJAR MATEMATIKA SISWA

\begin{tabular}{|c|c|c|c|c|c|c|}
\hline \multicolumn{7}{|c|}{ LSD } \\
\hline \multirow{2}{*}{ (I) JURUSAN } & \multirow{2}{*}{ (J) JURUSAN } & \multirow{2}{*}{$\begin{array}{c}\text { Mean } \\
\text { Difference (I- } \\
\text { J) }\end{array}$} & \multirow{2}{*}{ Std. Error } & \multirow{2}{*}{ Sig. } & \multicolumn{2}{|c|}{$95 \%$ Confidence Interval } \\
\hline & & & & & Lower Bound & Upper Bound \\
\hline \multirow[t]{4}{*}{ MIPA } & IPS & $38.696^{*}$ & 1.267 & .000 & 36.19 & 41.21 \\
\hline & PK & $38.783^{*}$ & 1.267 & .000 & 36.27 & 41.29 \\
\hline & BHS & $38.087^{*}$ & 1.267 & .000 & 35.58 & 40.60 \\
\hline & BIC & $8.783^{*}$ & 1.267 & .000 & 6.27 & 11.29 \\
\hline \multirow[t]{4}{*}{ IPS } & MIPA & $-38.696^{*}$ & 1.267 & .000 & -41.21 & -36.19 \\
\hline & PK & .087 & 1.267 & .945 & -2.42 & 2.60 \\
\hline & BHS & -.609 & 1.267 & .632 & -3.12 & 1.90 \\
\hline & BIC & $-29.913^{*}$ & 1.267 & .000 & -32.42 & -27.40 \\
\hline \multirow[t]{4}{*}{ PK } & MIPA & $-38.783^{*}$ & 1.267 & .000 & -41.29 & -36.27 \\
\hline & IPS & -.087 & 1.267 & .945 & -2.60 & 2.42 \\
\hline & BHS & -.696 & 1.267 & .584 & -3.21 & 1.81 \\
\hline & BIC & $-30.000^{*}$ & 1.267 & .000 & -32.51 & -27.49 \\
\hline \multirow[t]{4}{*}{ BHS } & MIPA & $-38.087^{*}$ & 1.267 & .000 & -40.60 & -35.58 \\
\hline & IPS & .609 & 1.267 & .632 & -1.90 & 3.12 \\
\hline & PK & .696 & 1.267 & .584 & -1.81 & 3.21 \\
\hline & BIC & $-29.304^{*}$ & 1.267 & .000 & -31.81 & -26.79 \\
\hline \multirow[t]{4}{*}{ BIC } & MIPA & $-8.783^{*}$ & 1.267 & .000 & -11.29 & -6.27 \\
\hline & IPS & $29.913^{*}$ & 1.267 & .000 & 27.40 & 32.42 \\
\hline & PK & $30.000^{*}$ & 1.267 & .000 & 27.49 & 32.51 \\
\hline & BHS & $29.304^{*}$ & 1.267 & .000 & 26.79 & 31.81 \\
\hline
\end{tabular}

*. The mean difference is significant at the 0.05 level.

Tabel 5. Hasil uji lanjut (Post Hoc) menggunakan uji LSD 
Kriteria uji lanjut (Post Hoc) dengan SPSS :

Sig. $<0.05$ maka terdapat perbedaan yang signifikan

Sig. > 0.05 maka tidak terdapat perbedaan yang signifikan

Dari uji Post Hoc dapat diketahui bahwa:

\begin{tabular}{|c|c|c|c|}
\hline (I) JURUSAN & & (J) JURUSAN & $\begin{array}{c}\text { Signifikansi hasil } \\
\text { belajar }\end{array}$ \\
\hline MIPA & & $\begin{array}{c}\text { IPS } \\
\text { PK } \\
\text { BHS } \\
\text { BIC }\end{array}$ & $\begin{array}{l}\text { Signifikan } \\
\text { Signifikan } \\
\text { Signifikan } \\
\text { Signifikan }\end{array}$ \\
\hline IPS & & $\begin{array}{c}\text { MIPA } \\
\text { PK } \\
\text { BHS } \\
\text { BIC }\end{array}$ & $\begin{array}{c}\text { Signifikan } \\
\text { Tidak Signifikan } \\
\text { Tidak Signifikan } \\
\text { Signifikan }\end{array}$ \\
\hline PK & 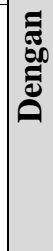 & $\begin{array}{l}\text { MIPA } \\
\text { IPS } \\
\text { BHS } \\
\text { BIC }\end{array}$ & $\begin{array}{c}\text { Signifikan } \\
\text { Tidak Signifikan } \\
\text { Tidak Signifikan } \\
\text { Signifikan }\end{array}$ \\
\hline BHS & & $\begin{array}{l}\text { MIPA } \\
\text { IPS } \\
\text { PK } \\
\text { BIC }\end{array}$ & $\begin{array}{c}\text { Signifikan } \\
\text { Tidak Signifikan } \\
\text { Tidak Signifikan } \\
\text { Signifikan }\end{array}$ \\
\hline BIC & & $\begin{array}{l}\text { MIPA } \\
\text { IPS } \\
\text { PK } \\
\text { BHS }\end{array}$ & $\begin{array}{l}\text { Signifikan } \\
\text { Signifikan } \\
\text { Signifikan } \\
\text { Signifikan }\end{array}$ \\
\hline
\end{tabular}

Tabel diatas menjelaskan tentang hubungan signifikasi masing-masing jurusan yang ada di MAN 1 Jember.

a. Jurusan MIPA

Jurusan MIPA memiliki signifikansi kurang dari 0.05 dengan jurusan IPS, PK, Bahasa, dan BIC, hal ini berarti bahwa terdapat perbedaan hasil belajar matematika siswa yang signifikan antara jurusan MIPA dengan empat jurusan lainnya (jurusan IPS, PK, Bahasa, dan BIC). 
b. Jurusan IPS

Jurusan IPS memiliki signifikansi kurang dari 0.05 dengan jurusan MIPA dan BIC, hal ini berarti bahwa terdapat perbedaan hasil belajar matematika siswa yang signifikan antara jurusan IPS dengan jurusan MIPA dan BIC. Selain itu, jurusan IPS memilki signifikansi lebih dari 0.05 dengan jurusan PK dan Bahasa, hal ini berarti bahwa tidak terdapat perbedaan hasil belajar matematika siswa yang signifikan antara jurusan IPS dengan jurusan PK dan Bahasa.

c. Jurusan PK

Jurusan PK memiliki signifikansi kurang dari 0.05 dengan jurusan MIPA dan BIC, hal ini berarti bahwa terdapat perbedaan hasil belajar matematika siswa yang signifikan antara jurusan PK dengan jurusan MIPA dan BIC. Selain itu, jurusan PK memilki signifikansi lebih dari 0.05 dengan jurusan IPS dan Bahasa, hal ini berarti bahwa tidak terdapat perbedaan hasil belajar matematika siswa yang signifikan antara jurusan PK dengan jurusan IPS dan Bahasa.

d. Jurusan Bahasa

Jurusan Bahasa memiliki signifikansi kurang dari 0.05 dengan jurusan MIPA dan BIC, hal ini berarti bahwa terdapat perbedaan hasil belajar matematika siswa yang signifikan antara jurusan Bahasa dengan jurusan MIPA dan BIC. Selain itu, jurusan Bahsa memilki signifikansi lebih dari 0.05 dengan jurusan IPS dan PK, hal ini berarti bahwa tidak terdapat perbedaan hasil belajar matematika siswa yang signifikan antara jurusan Bahasa dengan jurusan IPS dan PK.

e. Jurusan BIC

Jurusan BIC memiliki signifikansi kurang dari 0.05 dengan jurusan MIPA, IPS, PK, dan Bahasa, hal ini berarti bahwa terdapat perbedaan hasil belajar matematika siswa yang signifikan antara jurusan BIC dengan empat jurusan lainnya (MIPA, IPS, PK, dan Bahasa).

Dari hasil Post Hoc Tests Multiple Comparisons tersebut, maka didapatkan hasil bahwa jurusan MIPA dan BIC memiliki nilai yang signifikan terhadap juruan IPS, PK, dan Bahasa. Hal ini sesuai dengan data yang didapatkan dari hasil ulangan harian matematika kelas XI KD 3.3 tentang menjelaskan matriks dan kesamaan matriks dengan menggunakan masalah kontekstual dan melakukan operasi pada matriks yang meliputi penjumlahan, pengurangan, perkalian skalar, dan perkalian, serta transpose yang menyatakan bahwa hasil 
belajar matematika siswa pada jurusan MIPA dan BIC lebih unggul dari pada jurusan yang lain di MAN 1 Jember.

Jurusan MIPA dan BIC lebih unggul hasil belajar matematikanya disebabkan karena pada jurusan ini lebih ditekankan pembelajaran matematika yang lebih mendalam, contohnya terdapat mata pelajaran matematika peminatan yang mengkaji tentang pelajaran matematika yang lebih spesifik. Dalam penelitian ini, penulis mengambil data dari hasil ulangan harian matematika wajib dikarenakan mata pelajaran tersebut ada pada setiap jurusan.

\section{SIMPULAN DAN SARAN}

MAN 1 Jember merupakan Madrasah Aliyah Negeri di Kabupaten Jember yang terletak di J1. Imam Bonjol No.50, Kaliwates Kidul, Kaliwates, Kec. Kaliwates. Saat ini Madrasah tersebut telah memiliki lima jurusan yaitu MIPA, IPS, Program Keagamaan, Bahasa, dan BIC. Dari hasil uji statistic didapatkan hasil bahwa jurusan MIPA dan BIC memiliki nilai yang signifikan terhadap juruan IPS, PK, dan Bahasa. Jurusan MIPA dan BIC lebih unggul hasil belajar matematikanya disebabkan karena pada jurusan ini lebih ditekankan pembelajaran matematika yang lebih mendalam, contohnya terdapat mata pelajaran matematika peminatan yang mengkaji tentang pelajaran matematika yang lebih spesifik.

\section{DAFTAR PUSTAKA}

\section{Books:}

Ahmadi, Abu dan Widodo Supriyono. (2004). Psikologi Belajar. Cetakan kedua. Jakarta: Rineka Cipta.

Dahlan, Saronji. (2008). Seribu Pena Pendidikan Kewarganegaraan untuk SMP/MTs Kelas IX. Jakarta: Erlangga.

Dimyati dan Mudjiono. (2002). Belajar dan Pembelajaran. Jakarta: PT Rineka Cipta.

Fatimah. (2011). Fakto Penentu Obyektivitas dan Kreativitas. Majalah Ilmiah. EdisiMaretApril 2011. Sekretariat LPPM UNINDRA.

Hamalik, Oemar. (2009). Psikologi Belajar dan Mengajar. Bandung: PT Bumi Aksara.

Santoso, Soegeng. (2000). Problematika Pendidikan dan Cara Pemecahannya. Jakarta: Kreasi Pena Gading.

Shaleh, Abdul Rahman. (2009). Psikologi (Suatu Pengantar dalam Perspektif Islam. Jakarta: Prenada Media Group. 
133

Slameto. (2003). Belajar dan Faktor-faktor yang Mempengaruhi. Jakarta: PT Rineka Cipta.

Suriasumantri, J. S. (2009). Filsafat Ilmu (Sebuah Pengantar Populer). Jakarta: Pustaka Sinar Harapan. 